\section{Chronic interstitial nephritis: a long-term complication of} methylmalonic acid(MMÁ)-emin

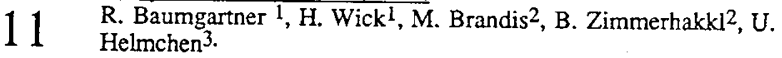

University Children's Hospitals Basel 1 and Freiburg/Br. 2 , Dept. Pathology, University Hamburg 3

In a girl with a $\mathrm{Cbl} \mathrm{A}$ mutant of MMA-emia treated since the neonatal period with a low protein diet, MMA conc, in urine (mol/mol creat.) varied from 0.9-3.5 ( $x=2.2)$ rising to max. 6.4 during infections. MMA plasma conc. (mmo//1) ranged from $0.1-0.4$, occasionally up to $1-3$. The patien was only partially $B_{12}$-responsive. The only two episodes of metabolic acidosis could easily be controlled. Physical and psychomotor development (IQ 100) was normal until $12 \mathrm{yrs}$ of age when growth retardation was noted. Laboratory studies revealed hyperuricemia $(560-780$ umol/h), low urinary uric acid and impaired creatinine clearance: $45 \mathrm{ml} / \mathrm{min} / .73 \mathrm{~m}^{2}$. Hypenuricemia normalized by allopurinol. By further restriction of protein intake $(0.5 \mathrm{~g} / \mathrm{kg} / \mathrm{d})$, oral OH-Cbl, 1-carnitine and alkali MMA levels could be reduced to $x=1.5 \mathrm{~mol} / \mathrm{mol}$ creat, and there was catch-up growth. At age $17 \mathrm{yrs}$ the girl was in good general health. Her renal function was: $C_{i n u l i n}: 54$ $\mathrm{ml} / \mathrm{min} / 1.73 \mathrm{~m}^{2}, \mathrm{CPAH}_{\mathrm{PAH}} 270 \mathrm{ml} / \mathrm{min} / 1.73 \mathrm{~m}^{2}$. Fractional excretion of sodium was increased to $5 \%$. Blood pressure was elevated $(145 / 100 \mathrm{mmHg})$. The renal biopsy showed a moderate foca interstitial nephritis with tubular atrophy, slight nephrosclerosis without glomerulonephritis, no urate deposits.

Conclusion: Chronic renal disease, not uncommon in patients with MMA-emia, may be caused by MMA itself or secondarily by hyperuricemia. In our case the renal function did not deteriorate over 5 years under a strict therapeutic regimen. MMA and urate levels must be carefully controlled in these patients. It remains to be shown whether the development of nephropathy can thus be prevented.

\section{2}

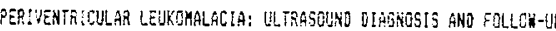
O.S. Saia, A.Yozzi, A.fiore, P. Griftith, L. ingunese, C.Ierzi, F. Cantarutti. Jepartaent of Pediatrics-University of Padid - ltaly.

Periventricular Laiknalacia (Py!) is fefined as ischesic infaretion of the *hite atter located arouad the lateral yentricles of the greastare inf int's brain. Fol is caused by the hyoper fusion of end arteries that supoly the white atter in the natarshed ateds betwean the a jor cerebral arterias.

Froa January 1984 to Detoker 1998, Sno iewborns kith a gestatiorial age 34 weeks, stailtad to HICl of Padua mere routinely scanned. Thirthy newborns $\left(5,9{ }^{*}\right)$ *ere diagnosed to have cavitar" PYL. Conconitant PYH-IVH occurred in 14 infants $(46.7 \%)$. Twent $\%$-seren babies survived and died. Trenty-four (90\%) of the 30 nemboras showed areas of increased echogenicity in the periventricular regions prior to the developsent of cystic changes. The aan age for the appearance of hyperechogenicity was 3 days irange $\mid-26)$. The aean age for the apgearance of cysts was 23 days (range 8-52). PUL was divided into localized and extensive lesions. Fimenty rewborns had Iocalized PK, 13 unilateral $(2$ frontal, 4 parietal 7 occipital) and 7 bilateral (2 frontal, 5 occipital). Ten nemborns had extensive and bilateral pll (B frontal, 9 parietal, 10 occipitall. Discharg̣ed babies were followed-up by repeated vitrasound scans. in 14 infants followed beyond $b$ antis postnatal age the cyits disappesead, ob they sere intill infants Fifteen infants had assc:iated aild-aodarate rentricuiar dilation, 5 had cerebral atroghy. ha 12 wenths icarrectas agel naurodevelopantal outcane of 17 garvivors $\mathrm{i}$; reported. Elaven bacias shiced cerabral palsy, 4 of thes had a sevare aental delay, ? a zodzrate aental delay ind 4 aera nerual. Fna bajy shoned a aild aotor deiay and a noral sentai developent. Five baties had a noral outor developaent, 1 of thas had a voterate aental delay and 4 nere norall. In conclusion, Plh is reisted with a poor neurodavelopaental nutcoae, garticularly when lezions are extensive, localizad and bilateral, above all when tha decigital lobe is envolved.

\section{Brain damage and recovery in hyperohenylalaninemia}

R. Surri, M. Vandevelde, J.M. Matthieu, F. Lazeyras,

13 N. Herschkowitz, University of Berne, Lausanne

Experimentally induced hyperphenylalaninemia (hyper-

phe) during the period of melinogenesis leads to a

decreased myelincontent in the rat brain. We asked the question whether this can be corrected if the animals are allowed to recover after the period of the brain growth spurt. Hyperphe was induced by injections of $\alpha$-Methylphenylalanine and phenylalanine from day 3 to 17 postnatally. Myelin related enzymes CST, CNP and myelin enriched glycolipids, Sulfatide and Cerebrosides were estimated biochemically at day 17 and after a period of recovery at day 59. The results are shown in TbI. 1. Values are given in mean and SD $n=12$.

\begin{tabular}{|c|c|c|c|c|c|}
\hline & & $\underset{(\mathrm{pmol} / \mathrm{h} / \mathrm{g})}{\mathrm{CST}}$ & $\underset{(m n o I / h / g)}{\text { CNP }}$ & $\begin{array}{l}\text { Cerebroside } \\
\text { (mg/司) }\end{array}$ & $\begin{array}{l}\text { Sulfatide } \\
(\mathrm{mg} / \mathrm{g})\end{array}$ \\
\hline Controls & $17 \mathrm{~d}$ & $348.6^{ \pm} 100.6$ & $8.20 \pm 1.20$ & $0.62-0.14$ & $0.11 \div 0.02$ \\
\hline Tests & $17 d$ & $201.8 \pm 69.3$ & $4.70 \pm 0.90$ & $0.23+0.06$ & $0.06 \div 0.02$ \\
\hline Controls & $59 d$ & $\begin{array}{l}<0.001 \\
152 . \pm^{ \pm} 21.5\end{array}$ & $\begin{array}{r}<0.001 \\
26.80 \pm 6.1\end{array}$ & $<0.001$ & $<0.001$ \\
\hline Tests & $59 \mathrm{~d}$ & $160.2^{ \pm} 17.7$ & $24.80 \div 7.6$ & $\begin{array}{l}6.59 \pm 1.51 \\
6.11-1.30\end{array}$ & $\begin{array}{l}1.33-0.29 \\
1.18 \pm 0.23\end{array}$ \\
\hline & & ns & ns & ns & ns \\
\hline
\end{tabular}
$\begin{array}{cccc}\text { ns } & \text { ns } & \text { ns } & \text { ns } \\ \text { There is a clear recovery of myelinogenesis at } 59 \text { days, which is }\end{array}$ corraborated by immunohistochemical staining. We conclude from our results, that catch up of myelinogenesis in experimental hyperphe is possible even after the period of the brain growth spurt.
Noninvasive assessment of maturation of corticospinal tract

\section{K. Muller, V. Hönterg, H. -G. Lenand}

Magnetolectrical stimulation of the motor cortex provides a noninvesive technique to study the normal development of the corticalspinal descending systom. Fifty children aged betheen 3 inonth and 10 years were studied. Using a Cadhell-MES10 magnetoelectric stimulator with a maximum magnetic
flux of 2 Tesla latencies of moto-responses after cortical and cervical or lunbar root stimulation were obtained fram thenar and abductor hallucis muscles. The latency differences between cortical and root stimulation provided an estimate of central conduction times for the fastest descending cortical spinal fibres.

central conduction times decreased down to the age of ten years before: reaching. adult values. Thresholds for cortical stimulation were significantly higher for lower extremity than for upper extremity muscies.

extremity than for upper extremity muscies.

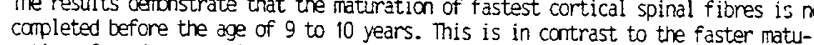
ration of conduction velocities in the peripheral nervous system as measured from cervical or lunbar root stimulation.

\section{PLEXUS \\ 15 K Winbladh, M Lindwall, C Nilsson, C Owman \\ Karolinska institute, Dept of Pediatrics, Sachs' \\ Children's Hospital, Stockholm and Dept of Histology, university of Lund, Sweden}

The cioroid plexus contains Na K-ATPase-dependent transport systems responsible for the production of the major part of the cerebral ventricular CSF. In aduit rabbits, treatment with betamethasone for 5 days decreases choroid plexus Na K-ATPase activity and consequently CSF production and in vitro choroid plexus transport capacity for choline. Choroia plexus Na K-ATPase activity is low in rabbit fetuses. A rapid increase starts at birth and adult levels are reached in around 3 weeks. This increase is parallelled by an increase in the in vitro transport capacity for choline (base) but not for penicilitin (acid). Kinetic studies showed to change in $K_{m}$ but an increase in $V_{\max }$ with age, suggesting that the same carrier system is involved in young and aduit animais. Administration of betamethasone to the in young and aduit animais. Administration of betamethasone to the choroid plexus Na K-ATPase activity and choline transport capacity by $58-81 \%$ and $35 \%$ respectively.
ANALYSIS OF CEREBROSPINAL FLUTD (CSF) FROM NEONATES USING PROTON MAGNETIC RESONANCE SPECTROSCOPY (MRS).

16 Jonathan M. Grigg, Peter M. Kilby, Peter L. Hope, George K. Radda. Dept of Paediatrics, John Radcliffe Hospital and Dept of Biochemistry, University of Oxford, Oxford, England.

Samples of CSF from 13 full-term newborn infants were studied using high resolution proton MRS. CSF $(0.5 \mathrm{mls})$ was stored at $-70^{\circ} \mathrm{C}$, freeze-dried, reconstituted in deuterium oxide and a marker added for quantitation and chemical shift referencing. Spectra were obtained at $300 \mathrm{MHz}$, using presaturation to suppress the water signal. Ten samples were from neurologically normal infants. Spectra showed peaks attributed to lactate, acetate, citrate, glutamine, glucose, alanine, 3-hydroxybutyrate, creatine, formate and inositol. Spectra from the CSF of 3 infants with postasphyxial encephalopathy and seizures showed a peak attributed to the drug carrier propylene glycol and another peak representing milimolar concentrations of unknown compound. Quantitative differences in the CSF spectra also occurred following asphyxia. difierences in the CSF spectrasphyxiated Asphyxiated CSF lactate (mmols/1) $1.16-3.33$ (med. 1.73 ) $2.49,2.52,11.76$ CSF glutamine (mmols/1) $0.47-1.09$ (med. 0.62 ) $1.16,1.33,1.85$

Non-selective assay of multiple metabolites using proton MRS may help to define CSF markers of cerebral ischaemia which would be suitable for conventional analysis. 